\title{
VARIABLE SUSCEPTIBILITY OF CYNOMOLGUS MONKEY KIDNEY CELLS TO THE SPECIFIC CYTOPATHIC EFFECT OF SIMIAN VIRUS 40
}

\author{
Michio ITO, MASAKo IKEGAMI, KAZUKo SHIROKI \\ AND ISAMU TAGAYA \\ Department of Enteroviruses, National Institute of Health, Tokyo
}

(Received: October 26th, 1964)

Simian virus 40 (SV40) has been well known to give rise to specific vacuoles in the cytoplasm of cultured kidney cells from special kinds of monkey, such as African green monkey (Sweet \& Hilleman, 1960), patas and baboon monkeys (Hsiung \& Gaylord, 1961). The remarkable accumulation of small vacuoles in the cytoplasm of infected cells is so characteristic that SV40 was given another name, the "vacuolating virus". It has been recognized that kidney cell cultures of rhesus monkeys show neither vacuolation of the cytoplasm nor any other signs of cytopathic effect (CPE), although characteristic nuclear changes were revealed by hematoxylin-eosin staining and a good yield of infectious particles was usually obtained in these cultures. No reliable observations on the growth of SV40 in cynomolgus monkey kidney cell cultures have ever been reported.

During the course of the studies on SV40 in our laboratory, it was found that some batches of cynomolgus monkey kidney cell cultures manifested characteristic vacuolation of the cytoplasm after infection with SV40, while other batches were apparently unaffected.

This communication deals with the mode of growth of SV40 in cynomolgus monkey kidney cells with evidence which determines the vacuolation in the cytoplasm as specific CPE caused by SV40.

\section{MATERIALS AND METHODS}

Virus: Strain 777 of SV40 was used in the present work, as described in the previous report (Ito et al., 1964). Virus stocks were prepared in primary-(GMK) and continuous African green monkey kidney (GMK-II) cells and MS (monkey stable) cells. They were coded as G-1 (1st GMK-passage of the seed virus sent from Dr. van Hoosier), GM-2, GM-6 (1st GMK-II-passage of G-1) and MS-4 (1st MS-passage of G-1), respectively. Their infective titers were about $10^{8.0_{-}}$ 108.5 $\mathrm{TCID}_{50} / \mathrm{cc}$, when titrated in primary GMK cell tube cultures.

Cell culture: Cynomolgus monkey kidney (CyMK) cells were trypsinized and cultured in tubes in a usual manner. Primary CyMK cultures were mainly employed in this work. A pair of kidneys from each monkey was processed separately (individual-batches) and in some cases kidneys from several monkeys were pooled for trypsinization (pooled-batches). The inoculated CyMK cells were maintained in Earle's balanced salt solution containing $0.5 \%$ lactalbumin hydrolysate and $0.22 \%$ sodium bicarbonate. Primary and continuous green monkey kidney cell cultures were also employed for the assay of infectivity (Ito et al., 1964).

Susceptibility of cynomolgus monkey kidney cells to SV4O: Each batch of CyMK cells was examined for its susceptibility to SV40. Four to five tube cultures were inoculated with $0.2 \mathrm{cc}$

伊藤道夫・池上正子・白木和子・多ケ谷勇（国立予防衛生研究所腸内ウィルス部） 
each of serial tenfold dilutions of the virus stock, and incubated at $35^{\circ} \mathrm{C}$. The cell cultures were observed from the 4th day on after inoculation and the appearance of characteristic vacuoles by SV40 was recorded. Virus titers were calculated by Reed-Muench formula at each observation time. The susceptibility of each cell batch was shown as the infective titer of the standard stock SV40 determined by the CPE endpoint in the respective cell cultures.

The preparation of the specific antiserum against SV40, the fluorescent antibody technique and the titration method of infectivity and neutralizing antibody were described in the previous report (Ito et al., 1964).

\section{EXPERIMENTAL RESULTS}

\section{The Development of the Specific Cytoplasmic Vacuolation in Cynomolgus Monkey Kidney Cell Cultures by SV4O Infection}

One of the standard SV40 stocks (Code: G-1, MS-4, GM-2 or GM-6) was inoculated into each batch of primary CyMK cell cultures for the titration of infectivity as revealed by vacuolation in the cytoplasm. A total of 54 batches of CyMK cells were examined. The results are shown in Table 1. In some batches of CyMK cultures was observed characteristic vacuolation of the cytoplasm, which is indistinguishable from that observable in GMK cultures, whereas other batches showed either no such CPE even in tube cultures inoculated with the lowest dilution $\left(10^{-1}\right)$ of the stock virus, or sometimes, in cultures inoculated with a low dilution of the virus suspension, a sort of CPE, i. $e$. granulation and rounding of cells, which is different from typical vacuolation. The highest infective titers of the standard virus in CyMK cells were $10^{6.0}-10^{6.5} \mathrm{TCID}_{50} / 0.2$ $\mathrm{cc}$ as determined by the most clear formation of vacuoles (Plate-Figs. 2 and 3). This

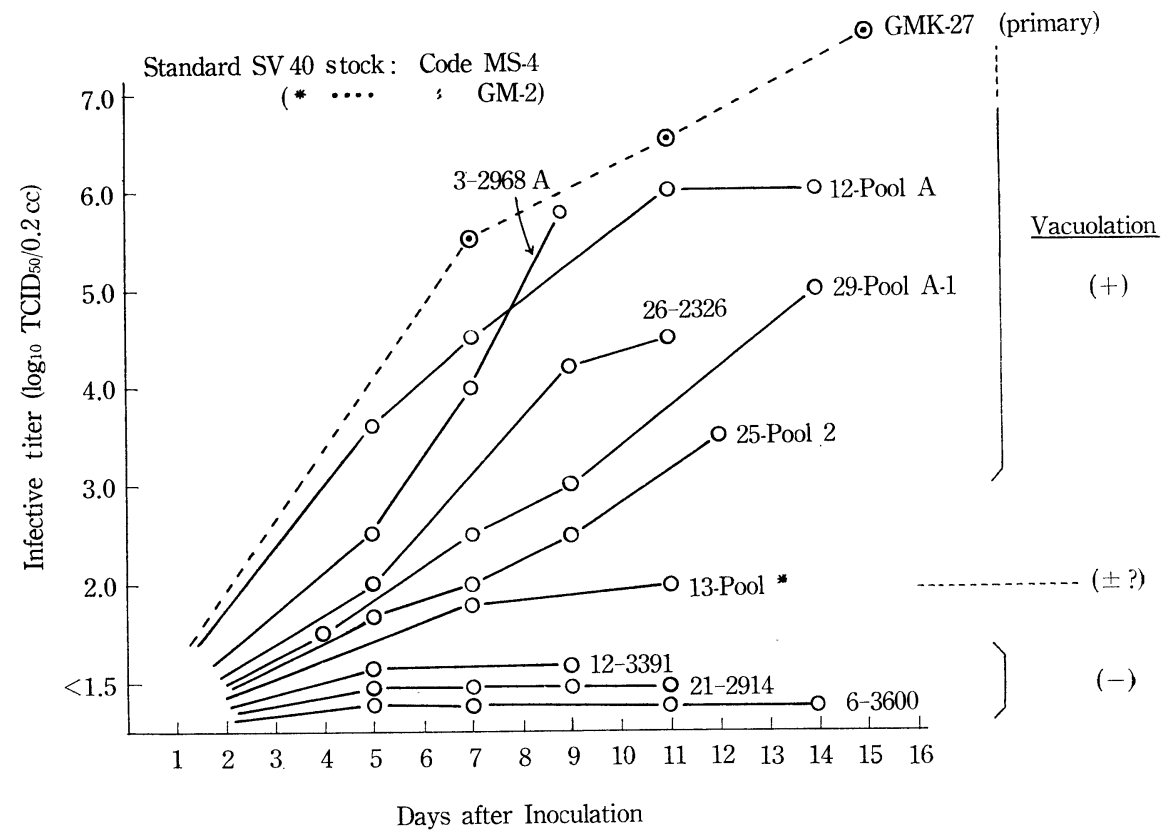

Fig. 1. Progress of the infective titer of a standard SV40 stock virus in different batches of cynomolgus monkey kidney cell cultures as determined by vacuolation in the cytoplasm. 
Table 1. The specific CPE of SV40 in each batch of cynomolgus monkey kidney cells

\begin{tabular}{|c|c|c|c|c|c|c|}
\hline \multirow{2}{*}{ No. } & \multirow{2}{*}{$\begin{array}{l}\text { Code of CyMK } \\
\text { cell batch }\end{array}$} & \multirow{2}{*}{$\begin{array}{l}\text { Seed virus } \\
\text { code } \\
\text { of SV40 }\end{array}$} & \multicolumn{2}{|c|}{ SV40 titer in each batch } & \multirow{2}{*}{$\begin{array}{c}\text { Specific } \\
\text { CPE of SV40 }\end{array}$} & \multirow{2}{*}{ Remarks } \\
\hline & & & $5-8$ th day & $9-14$ th day & & \\
\hline 1 & $15-3001$ & G-1 & 3.0 & 4.0 & + & \\
\hline 2 & $24-2810$ & MS-4 & $2.0 ?$ & ? & ? & FA** \\
\hline 3 & 29-Pool A-1 & 11 & 2.5 & 5.0 & $\dot{t}$ & $\mathrm{FA}$ ? \\
\hline 4 & 29-Pool A-2 & "I & 2.5 & 5.0 & + & \\
\hline 5 & $29-2974$ & "I & 4.0 & 5.0 & + & \\
\hline 6 & $12-3391$ & "I & $<1.5$ & $(1.5 ?)$ & - & R. C. $* * *$ \\
\hline 7 & $12-3396$ & $" 1$ & 3.0 & 4.0 & + & N. \\
\hline 8 & 12-Pool A & "I & 4.5 & 6.0 & + & \\
\hline 9 & $26-2326$ & "I & 2.0 & 4.5 & + & \\
\hline 10 & $26-3195$ & "I & 2.0 & 5.5 & + & \\
\hline 11 & $26-3297$ & $" 1$ & $<1.5$ & $<1.5$ & - & \\
\hline 12 & $3-3091$ & "1 & $<1.0$ & $<1.0$ & - & R. C. \\
\hline 13 & $3-2919$ & "I & $<1.0$ & $<1.0$ & - & \\
\hline 14 & 3-2968 A & $" 1$ & 4.0 & 6.0 & + & \\
\hline 15 & $3-3373 \mathrm{~B}$ & "I & $(1.5)$ & (1.5) & - & R. C. \\
\hline 16 & $3-3216$ B & "I & $<1.0$ & $?$ & $-?$ & \\
\hline 17 & 3-Pool A & "I & $(1.0)$ & $(1.0)$ & - & FA, R. C. \\
\hline 18 & $3-3344$ & $" 1$ & 3.5 & 5.5 & + & \\
\hline 19 & $21-2914$ & "I & $(1.5)$ & $(1.5)$ & - & R. C. \\
\hline 20 & $21-3101$ & "I & (1.3) & $(2.5)$ & - & R. C. \\
\hline 21 & $21-3114$ & "I & 3.3 & 4.3 & + & \\
\hline 22 & $21-3177$ & "1 & 2.5 & 4.5 & + & \\
\hline 23 & $25-3755$ & $" \prime$ & $<1.0$ & (1.5) & - & R. C., FA \\
\hline 24 & 25-Pool-1 & "I & 3.2 & 4.5 & + & ח. \\
\hline 25 & 25-Pool-2 & "I & 2.0 & 3.5 & + & \\
\hline 26 & 6-Pool A & $" 1$ & 1.5 ? & $2.3 ?$ & $?$ & R. C. \\
\hline 27 & $6-3574$ & " & $<1.0$ & $<0.5$ & $\dot{-}$ & \\
\hline 28 & $6-3600$ & "I & $<1.0$ & $<0.5$ & - & \\
\hline 29 & $6-1574$ & " & 1.7 & 3.5 & + & \\
\hline 30 & $13-\quad 3$ & GM-2 & $<1.0$ & $<1.0$ & $\overline{2}$ & \\
\hline 31 & 13-Pool & " & $2.0 ?$ & $2.0 ?$ & ? & \\
\hline 32 & 3656 & GM-2 & $2.0 ?$ & ? & ? & SV ?**** \\
\hline 33 & $10-3885$ & "I & $<1.0$ & $(3.7)$ & $\dot{-}$ & R. C. \\
\hline 34 & $10-3612$ & " & $<1.0$ & (1.5) & - & R. C. \\
\hline 35 & $10-3878$ & "I & 3.3 & $>6.5$ & + & \\
\hline 36 & $17-3768$ & "I & $(3.0)$ & $(4.2)$ & - & R. C. \\
\hline 37 & $17-3010$ & "I & $<1.0$ & $(2.0)$ & - & R. C. \\
\hline 38 & $22-3336$ & " & 2.5 & 6.0 & + & \\
\hline 39 & 5-Pool A & " & 2.7 & 4.7 & + & \\
\hline 40 & 5-Pool B & $" \prime$ & 4.0 & 5.7 & + & \\
\hline 41 & 5-Pool D & $" \prime$ & 3.5 & 4.0 & + & \\
\hline 42 & 5-Pool C & " & 2.3 & $?$ & $+?$ & \\
\hline 43 & 5-3995 & "1 & 2.5 & 6.5 & + & \\
\hline 44 & $5-3989$ & "I & 2.3 & 6.0 & + & \\
\hline 45 & $5-3992$ & "I & $<1.0$ & (1.8) & - & R. C. \\
\hline 46 & 12-Pool A & " & 4.5 & 6.2 & + & \\
\hline & $3-5108$ & GM-6 & 4.0 & 6.2 & + & \\
\hline 48 & $3-3694$ & " & 3.5 ? & ? & $+?$ & \\
\hline 49 & $3-5112$ & " & 4.8 & ? & + & \\
\hline 50 & $3-4918$ & " & $<1.0$ & ? & -? & \\
\hline 51 & $9-5328$ & "I & $<1.0$ & $<1.0$ & - & \\
\hline 52 & $9-5331$ & " & 1.5 ? & $?$ & $?$ & FA \\
\hline 53 & $9-5341$ & " & 1.8 & 2.6 & $+?$ & \\
\hline 54 & $9-5370$ & " & $1.4 ?$ & $1.5 ?$ & ? & FA \\
\hline
\end{tabular}

* TCID $_{50} / 0.2 \mathrm{cc}$.

** FA : foamy degeneration.

*** R. C. : cell rounding.

SV40 titer in parentheses means that determined by CPE without vacuolation (cell rounding). SV40 titer with a question mark means that the end-point was not so clear because CPE was not so typical.

**** $\mathrm{CPE}$ was obscured by non-specific degeneration 'of cells which was also observed in the control non-infected cultures. 
kind of cytoplasmic vacuoles appeared as a rule from on the 3rd to on the 5th day after inoculation, and progressed slowly up to the 14th day (Text-Fig. 1). Usually the observation was discontinued around 14 days after infection, because at that time the control cell cultures became degenerated to various grades, rendering the observation of delicate CPE of SV40 obscure. The progress of the characteristic CPE was slightly delayed in CyMK cells than in primary GMK cells, and scarcely involved the whole cell sheet as was the case with the latter cells. An accurate observation was frequently disturbed by a foamy or other non-specific degeneration of the cells. The results shown in Table 1 are summerized in Table 2. Eighteen (44\%) out of 41 individual batches of CyMK cells examined showed characteristic CPE (specific vacuolation), 19 batches (46\%) were negative and 4 batches $(10 \%)$ were doubtful. Nearly one half of the individual cell batches examined showed cytoplasmic vacuoles of the same character as were observable in GMK cells infected with SV40. On the other hand, $10(77 \%)$ of 13 pooled-batches proved to form characteristic vacuoles and only one $(8 \%)$ was negative. It seems that batches of pooled CyMK cells showed characteristic CPE of SV40 more frequently than individual batches. This will be discussed later. Another type of CPE (granulation and cell-rounding) was observed in tube cultures of the same batches of CyMK cells that were inoculated with lower dilutions (less than about $10^{-4}$ dilution) of the stock SV40. This indistinct CPE also seemed to be accounted for by the infection with SV40, but could not be confirmed.

Table 2. Frequency of the specific CPE occurrence in cell batches of cynomolgus monkey kidney cultures tested

\begin{tabular}{ccccc}
\hline & \multicolumn{3}{c}{ Cytoplasmic vacuoles } & \multirow{2}{*}{ Total } \\
\cline { 2 - 4 } Number of cell batches & + & - & Doubtful & \\
\hline Individual cell batch & $18(44 \%)$ & $19(46 \%)$ & $4(10 \%)$ & 41 \\
Pooled cell batch & $10(77 \%)$ & $1(8 \%)$ & $2(15 \%)$ & 13 \\
\hline Total & 28 & 20 & 6 & 54 \\
\hline
\end{tabular}

Table 3. Specific inhibition of SV40 CPE in cynomolgus monkey kidney cells by neutralizing the inoculum with the antiserum against SV40

\begin{tabular}{cccccc}
\hline \multirow{2}{*}{ MK cell batch } & \multicolumn{2}{c}{ Without antiserum } & & \multicolumn{2}{c}{ With antiserum } \\
\cline { 2 - 3 } \cline { 2 - 3 } & $\begin{array}{c}\text { SV40 titer } \\
\text { (12th day })\end{array}$ & Sp. CPE & & $\begin{array}{c}\text { SV40 titer } \\
\text { (12th day) }\end{array}$ & Sp. CPE \\
\hline $25-3755$ & $<0.5^{*}$ & - & + & $<0.5$ & - \\
$25-$ Pool-1 & 4.5 & + & & $<0.5$ & - \\
$25-$ Pool-2 & 3.5 & + & & $<0.5$ & - \\
\hline
\end{tabular}

* $\mathrm{TCID}_{50} / 0.2 \mathrm{cc}$.

SV40 seed virus, GM-2, was used in this experiment.

\section{The Specific Inhibition of Cytoplasmic Vacuolation in Cynomolgus Monkey Kidney Cells by Anti-SV4O Serum}

It was then examined whether the vacuolation of cells was specifically related with the infection of SV40. When SV40 was previously neutralized with the corresponding 
antiserum before inoculation, the characteristic CPE in the positive CyMK batches was inhibited completely (Table 3). Consequently it was substantiated that vacuoles observed in CyMK cells infected with SV40 were specific changes caused by the virus.

\section{Relationship between Immune State of Cynomolgus Monkeys Against SV4O and Susceptibility of Their Kidney Cells to the Specific CPE}

In Table 1 are included two kidney cell batches (13-3, 13-pool) prepared from kidneys of monkeys, which had been hyperimmunized against SV40. Consequently a possibility should be taken into consideration that the negative CPE in these two batches is accounted for by the immune state of the monkeys, from which kidneys were taken out. Cynomolgus monkeys had been imported from Malaya, Cambodia and South Vietnam, but no attempt had ever been made at that time to examine the existence of antibody against SV40 in the sera of cynomolgus monkeys received in our laboratory. Four monkeys were chosen for the titration of antibody against SV40, of which two afforded kidney cell cultures with positive CPE of SV40, while the other two supplied those without any characteristic vacuolation. The results are shown in Table 4. All the four monkeys

Table 4. Lack of SV40 antibody in the monkeys, of which kidney cells are not susceptible to the specific CPE of SV40

\begin{tabular}{ccccc}
\hline Monkey No. & $\begin{array}{c}\text { Neutralizing antibody } \\
\text { titer against SV40 }\end{array}$ & $\begin{array}{c}\text { Derived } \\
\text { cell batch }\end{array}$ & $\begin{array}{c}\text { SV40 titer } \\
\text { (12th day) }\end{array}$ & $\begin{array}{c}\text { Specific } \\
\text { CPE }\end{array}$ \\
\hline 2914 & $<4$ & $21-2914$ & $<1.5^{*}$ & - \\
3101 & $<4$ & $21-3101$ & $<1.3$ & - \\
3114 & $<4$ & $21-3114$ & 4.3 & + \\
3177 & $<4$ & $21-3177$ & 4.5 & + \\
\hline
\end{tabular}

* SV40 titer of the seed virus, GM-2, measured in each CyMK cell batch $\left(\mathrm{TCID}_{50} / 0.2 \mathrm{cc}\right)$.

examined had no detectable antibody against SV40. This indicates that the negative $\mathrm{CPE}$ in some CyMK cell batches had no relation to the existence of specific humoral antibody in the animals, from which kidneys were obtained.

\section{Frequency of SV4O Antigen-Containing Cells in the Specific CPE-Positive or -Negative Cynomolgus Monkey Kidney Cells}

Percentage of cells actually infected with SV40 was examined in both the vacuolepositive and -negative cell batches by means of the fluorescent antibody technique. The specific antigen of SV40 was easily observed in the nucleus of the infected CyMK cells as was the case with GMK cells (Ito et al., 1964). The results of experiments in primary and secondary cultures of CyMK cells are shown in Table 5. The fluorescent cell ratio was about $1-6 \%$ of the whole cell population on the 1st-2nd day and about $30-40 \%$ on the 4th day after infection at a high input multiplicity. No significant difference could be observed in the frequency of the viral antigen-containing cells between specific CPE-positive and -negative cell batches. 
Table 5. Frequency of SV40 antigen-containing cells in the specific CPE-positive or -negative cynomolgus monkey kidney cell cultures

\begin{tabular}{|c|c|c|c|c|}
\hline \multirow{2}{*}{ MK cell batch } & \multirow{2}{*}{$\begin{array}{l}\text { SV40 titer* } \\
\text { (9-14th day) }\end{array}$} & \multirow{2}{*}{$\begin{array}{l}\text { Specific } \\
\text { CPE }\end{array}$} & \multicolumn{2}{|c|}{ Fluorescent antibody staining } \\
\hline & & & $\begin{array}{c}\text { Day after } \\
\text { infection }\end{array}$ & $\begin{array}{l}\text { Per cent** } \\
\text { positive }\end{array}$ \\
\hline \multicolumn{5}{|c|}{ Exp. 1 Primary cultures } \\
\hline $21-2914$ & $<0.5(1.5) * * *$ & - & 2nd day & $2.8 \%$ \\
\hline $21-3101$ & $<0.5(2.5)$ & - & $\prime \prime$ & 3.7 \\
\hline $21-3114$ & 4.3 & + & $\prime \prime$ & 2.7 \\
\hline $21-3177$ & 4.5 & + & $\prime \prime$ & 6.0 \\
\hline \multicolumn{5}{|c|}{ Exp. 2 Secondary cultures } \\
\hline $17-3768$ & $<1.0$ & - & $\begin{array}{l}\text { 1st day } \\
\text { 4th day }\end{array}$ & $38.0 \%$ \\
\hline $22-3336$ & 4.0 & + & $\begin{array}{l}\text { 1st day } \\
\text { 4th day }\end{array}$ & 32 \\
\hline
\end{tabular}

* SV40 titer of the seed virus, GM-2, measured in each cell batch $\left(\right.$ TCID $_{50} / 0.2 \mathrm{cc}$ ).

** Per cent fluorescent cells calculated from the count of a total of 500-1000 cells.

*** See footnote in Table 1.

Table 6. Yield of SV40 virus in the specific CPE-positive or -negative cynomolgus monkey kidney cell batches

\begin{tabular}{|c|c|c|c|c|c|}
\hline \multirow{2}{*}{\multicolumn{2}{|c|}{ Cell batch }} & \multirow{2}{*}{$\begin{array}{l}\text { Specific } \\
\text { CPE }\end{array}$} & \multicolumn{2}{|c|}{ SV40 virus yield in each cell batch } & \multirow{2}{*}{$\begin{array}{l}\text { Control } \\
\text { culture } \\
\text { fluid }\end{array}$} \\
\hline & & & \multicolumn{2}{|c|}{ Culture fluid inoculated with the SV40 seed (GM-2) } & \\
\hline \multirow[t]{4}{*}{ Exp. $1^{*}$} & $21-2914$ & - & $6.0^{* * *}$ & & $<1.0$ \\
\hline & $21-3101$ & - & 6.0 & & $<0.5$ \\
\hline & $21-3114$ & + & 5.5 & & $<0.5$ \\
\hline & $21-3177$ & + & 6.5 & & $<0.5$ \\
\hline \multirow[t]{2}{*}{ Exp. $2^{*}$} & $10-3878$ & + & 7.5 & 7.5 & $<1.5$ \\
\hline & $10-3885$ & - & 7.5 & 6.8 & $<1.5$ \\
\hline
\end{tabular}

* SV40 titer of the infected MK culture fluids (harvested at 13th day) was measured in GMK-II (37th passage) cells.

** SV40 titer of the culture fluids (harvested at 14th day) was measured in GMK-II (45th passage) cells. Sensitivity of these passaged GMK-II cells against SV40 was somewhat variable at each passage level.

*** $\mathrm{TCID}_{50} / 0.2 \mathrm{cc}$.

\section{Multiplication of Infectious Particles of SV4O in the Cultures of Specific CPE-Positive or -Negative Cell Batches}

As shown in Table 6, infectivity of SV40 in the culture fluids of both CPE-positive and -negative tubes infected with $10^{-2}$ and $10^{-5}$ diluted stock virus (GM-2) was titrated employing GMK-II cell tube cultures. Uninoculated CyMK cell cultures did not contain any detectable infectivity of SV40, indicating that cynomolgus monkeys quarantined in our Institute have not had any inapparent infection of SV40. A high infectivity was constantly found in both types of CyMK cells in a similar manner as in GMK cell 
cultures infected with SV40. It was thus revealed that there was no difference in the yield of infectious particles of SV40 between CPE-positive and -negative cell cultures.

\section{Susceptibility of Secondary Cultures of Cynomolgus Monkey Kidney Cells to the Specific CPE of SV4O}

Since it was shown that the capacity of some cell cultures to develop vacuoles by SV40 infection was independent of the SV40 synthesizing capacity, the next experiment was designed to examine whether the capacity of certain CyMK cultures to react to SV40 infection with or without vacuolation could be transferred to the secondary cultures. Secondary CyMK cell cultures were prepared by the subculture of 6-days-old primary cultures, and when monolayers were obtained, they were infected with SV40. Comparison was made regarding the infectivity titers of the inoculum as determined by the specific $\mathrm{CPE}$ or non-vacuolating $\mathrm{CPE}$ in both primary and secondary cultures. The results are given in Table 7 . The CPE negative cell batches in primary cultures were always negative in the secondary culture, and the CPE positive batches remained sensitive to SV40 vacuolation in the subculture. The results indicated that the susceptibility of CyMK cells to the specific CPE of SV40 could be considered as a hereditary entity of the cells.

Table 7. The specific CPE of SV40 in secondary cultures of cynomolgus monkey kidney cells

\begin{tabular}{ccccccc} 
& \multicolumn{2}{c}{ Primary cells } & & \multicolumn{2}{c}{ Secondary cells* } & \multirow{2}{*}{ Cell batch } \\
\cline { 2 - 3 } & SV40 titer & Specific CPE & & SV40 titer & Specific CPE & Remarks \\
\hline 17-3768 & $<1.0(4.2)^{* *}$ & - & & $<1.0$ & - & \\
$17-3010$ & $<1.0(2.0)$ & - & & $<1.0$ & - & \\
$22-3336$ & 6.0 & + & & 4.0 & + & FA*** \\
5-Pool A & 4.7 & + & & $2.5(4$ th day $)$ & + & FA \\
5-Pool B & 5.7 & + & & 5.5 & + & \\
5-Pool D & 4.5 & + & & 4.7 & + & \\
\hline
\end{tabular}

* Secondary cell cultures were prepared by subculturing 6-day old primary cultures.

** See footnote in Table 1.

*** See footnote in Table 1.

\section{An Attempt to Convert the CPE Negative MK Cells into the CPE Positive Cells by Pretreatment with an Extract of the CPE Positive Cells}

As described in the previous section, pooled cell batches were observed to show specific vacuoles in the cytoplasm more frequently than individual cell batches after SV40 infection (Table 2). By pooling several individual cell batches, it was revealed that the development of the specific $\mathrm{CPE}$ in this pooled cultures was dependent on the most susceptible cell batch constituting the pool. A possibility remained to be elucidated that the susceptible cells have certain factors which could convert non-susceptible cells of the pool cultures into susceptible ones, as reported by Kantoch et al. (1963) with mouse macrophage cultures concerning the infection of mouse hepatitis virus. The effect of an extract of susceptible CyMK cells on the non-susceptible cultures concerning vacuolation 
by SV40 was examined. The method of preparation of cell extract and the procedure of the pretreatment of non-susceptible cells with the extract were carried out after the description of Kantoch et al. (1963). Even when the CyMK cell cultures were pretreated with the extract of the $\mathrm{CPE}$ positive cells, no change could be observed in the cellular reactivity concerning vacuolation by SV40.

\section{Relationship between the Specific Vacuolation of SV4O and the Spontaneous Foamy Degeneration of Cynomolgus Monkey Kidney Cell Cultures}

The condition of cell degeneration (foamy degeneration), frequently referred to as "foamy agent", was sometimes observed in CyMK cell cultures throughout the present studies, in which were frequently observed large polynuclear giant cells containing vacuoles of foamy appearance. Those vacuoles were usually large and not so difficult to be differentiated from the specific CPE of SV40 in typical cases, which is characterized by a massive accumulation of small vacuoles within the whole cytoplasm. When susceptible CyMK cell cultures showing the foamy degeneration were inoculated with SV40, the specific cytoplasmic vacuolation by SV40 was sometimes noticed in giant cells containing "foamy vacuoles". These results seemed to show that no interference occurred between SV40 and "foamy agent" infection. At that time polynuclear giant cells were observed to include intranuclear inclusion bodies demonstrable by hematoxylin-eosin staining, indicating that the cells were doubly-infected, because the foamy degeneration of CyMK cells does not accompany any intranuclear inclusion bodies, while SV40-infected cultures do not show any polynuclear giant cells. The problem on the interrelation of two viruses was not studied further, since the "foamy agent" had not been successfully subcultured in our laboratory, as stated by Hull \& Minner (1957).

\section{DISCUSSION}

Cynomolgus monkey kidney cell cultures were found to be differently susceptible to SV40 in regard to the formation of characteristic vacuoles in the cytoplasm. The reason remained so far unknown why some cell batches were sensitive to the CPE while the other were not. The susceptibility of the cells concerning the development of vacuolation has nothing to do with the immune state of monkeys, the frequency of actually infected cells in the total cell population or the yield of infective particles in the cultures. Primary cell cultures showing the specific CPE were also susceptible even in the secondary culture, suggesting that this phenomenon might depend on a difference in some hereditary character(s) carried by CyMK cells of individual monkeys. It might be possible that CyMK cell cultures are a mixed population of both CPE-positive and -negative cells, and one type of the characters might be chiefly expressed in the infected cell cultures when the corresponding type of the cells are dominant in the culture. It seems almost impossible to differentiate these cells morphologically, and no positive evidence to support this hypothesis could be obtained.

Cynomolgus monkey kidney cells were found to be infected effectively by SV40 with a good yield of infectious virus as was the case with GMK or rhesus MK cells. The viral antigen was frequently observed in the nucleus of infected CyMK cells in a similar manner as in GMK cells (Hans, 1963 and Ito et al., 1964) and rhesus MK cells (Shein et al., 1962). It appears that in CyMK cells growth of SV40 proceeds quite well regardless of the formation of characteristic vacuoles in the cytoplasm. Adenovirus is 
known to have a toxic factor different from infectious particles and complement-fixing antigens (Rowe et al., 1958 ; Pereira, 1958; Everett \& Ginsberg, 1958). In this case cell-degeneration is considered to take place by the direct action of the toxic factor, and the intracellular development of adenovirus does not always seem to be necessary for the manifestation of CPE. This indicates that the viral CPE is not necessarily related with the intracellular multiplication of infectious particles. It was reported in the previous report (Ito et al., 1964) that the cytoplasmic vacuolation by SV40 seemed to take place in coincidence with the time when newly-formed virus particles became transferred from the nucleus to the cytoplasm and released into the culture fluid. It is unknown, however, whether the vacuolation is directly related with the release of virus particles synthesized in the nucleus through the cytoplasm. On the other hand, it is known that SV40 multiplies in some kinds of cells without any vacuolation of the cytoplasm. Therefore, it is suggested that at least two possible factors might be implicated for the appearance of cytoplasmic vacuoles; one may be a specific cellular factor, which concerns the reactive capacity of cells to SV40 infection, probably one of genetic entities, and the other may be a viral factor, or a sort of stimulus brought about by SV40 infection. When these two factors work in combination, cytoplasmic vacuolation might be observed. An important role of the cellular factor for the manifestation of vacuolation by SV40 appears to deserve special emphasis. In rhesus monkey kidney cells or CPE-negative cynomolgus monkey kidney cells, the cellular factor might be defective or masked. As was shown by Kantoch et al. (1963) with mouse macrophages and mouse hepatitis virus, an attempt was made to find, if any, soluble factor(s) in the extract of CPE-positive CyMK cells which might convert CPE-negative cells susceptible to vacuolation by SV40, but without any promising results. There is an important difference between these two cases that any viral production was scarcely observable in non-sensitive $\mathrm{C} 3 \mathrm{H}$ cells inoculated with mouse hepatitis virus (Kantoch et al., 1963), whereas in CyMK cellsSV40 interaction virus growth was considered to proceed in a similar manner both in vacuolating and non-vacuolating cells. Vacuolation in the cytoplasm as a result of SV40 infection appears to offer another intricate problem concerning host-virus interaction.

Foamy degeneration of CyMK cells was often observed in the cell batches used in the present work, which is considered inevitable as far as cynomolgus monkey kidney cells are used. Morphologically, vacuolation by SV40 and spontaneous foamy degeneration were observed in the same cell, suggesting no interference between SV40 and "foamy agent". This phenomenon had been already suggested by Plummer (1963).

\section{SUMMARY}

The specific vacuolation was found in the cytoplasm of some batches of cynomolgus monkey kidney cells following SV40 infection, which was indistinguishable from that observed in African green monkey kidney cells. But the other batches of the cells examined did not show any such cytopathic effect. Both types of the cynomolgus monkey kidney cell cultures supported equally a full growth of SV40. The susceptibility to SV40-vacuolation was supposed to be one of the special cellular characters which might be genetically controlled.

\section{REFERENCES}

Everett, S. F. \& GinsBerg, H. S. (1958): A toxinlike material separable from type 5 adenovirus particles. Virology, 6, 770-771. 
HANS, D. (1963) : A fluorescent antibody study on the formation of simian virus 40 in monkey kidney cells. Acta path. et microbiol. Scandinav., 57, 348-352.

Hsuing, D. G. \& GAYLORD, W. H. (1961): The vacuolating virus in monkeys. I. Isolation, growth characteristics, and inclusion body formation. J. Exper. Med., 114, 975-986.

Hull, R. N. \& MinNeR, J. R. (1957): New viral agents recovered from tissue cultures of monkey cells. II. Problems of isolation and identification. Ann. New York Acad. Sci., 67, 413-423.

Ito, M., Ikegami, M., Shiroki, K. \& Tagaya, I. (1964): Studies on the multiplication of simian virus 40 (vacuolating virus) by means of fluorescent antibody technique. Jap. J. M. Sci. \& Biol., 17, 179-193.

KANTOCH, M., WARWICK, A. \& BANG, F. B. (1963) : The cellular nature of genetic susceptibility to a virus. J. Exper. Med., 117, 781-797.

PereirA, H. G. (1958): A protein factor responsible for the early cytopathic effect of adenoviruses. Virology, 6, 601-611.

Plummer, C. (1963) : Interfering properties of simian viruses. Brit. J. Exper. Path., 44, 58-65.

Rowe, W. P., Hartley, J. W., Roizman, B. \& Levy, H. B. (1958): Characterization of a factor formed in the course of adenovirus infection on tissue cultures causing detachment of cells from glass. J. Exper. Med., 108, 713-729.

Shein, H. M. \& Levinthal, J. D. (1962): Fluorescent antibody and complement fixation tests for detection of SV40 virus in cell cultures. Virology, 17, 596-597.

SweEt, B. H. \& Hilleman, M. R. (1960): The vacuolating virus SV40. Proc. Soc. Exper. Biol. \& Med., 105, 420-427. 


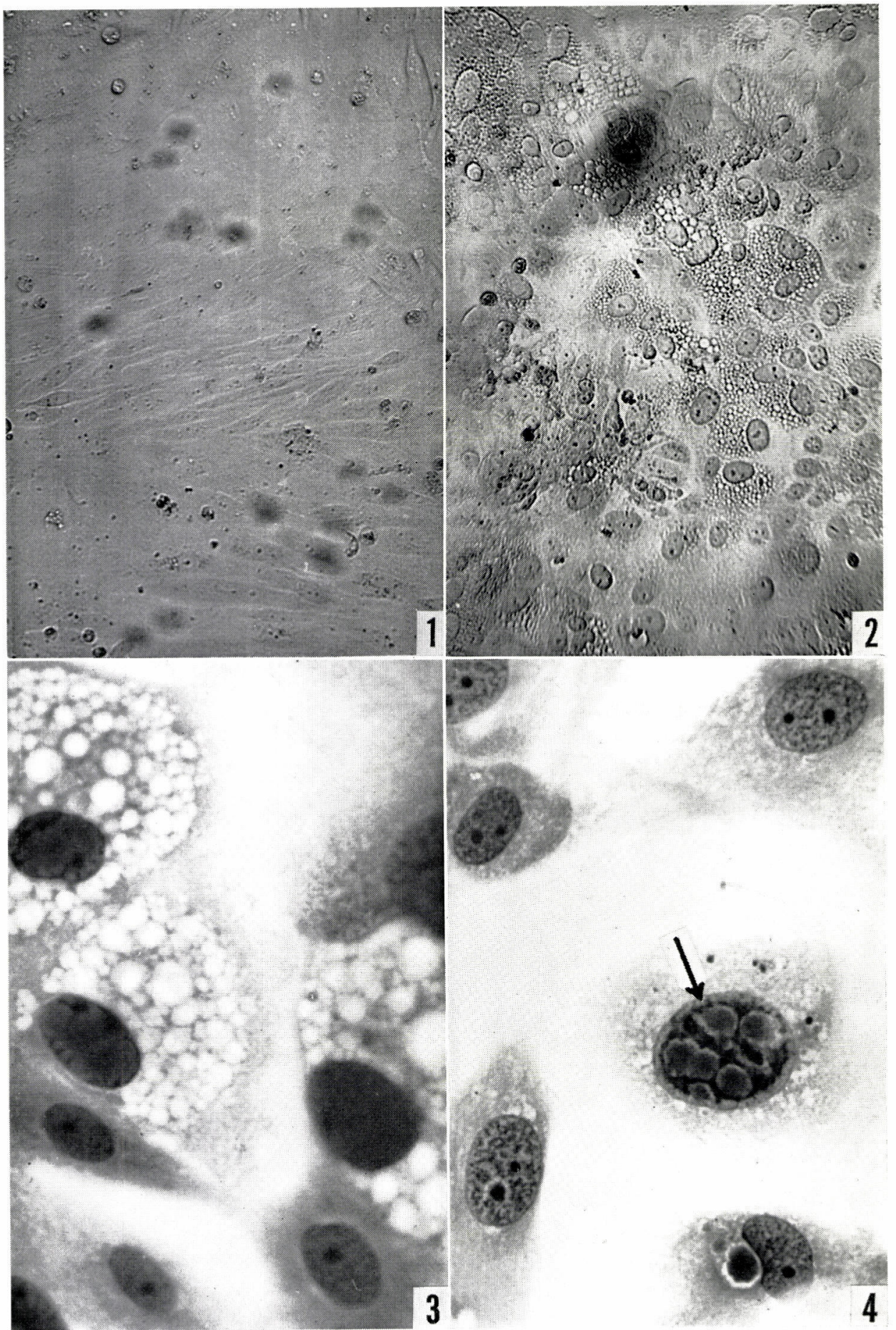




\section{Explanation of Plate-Figs}

Fig. 1. Untreated cynomolgus monkey kidney cell culture, unstained, $\times 150$.

Fig. 2. Typical cytoplasmic vacuolation in a sensitive batch of cynomolgus monkey kidney cell culture infected with SV40 (5th day following inoculation), unstained, $\times 150$.

Fig. 3. Typical cytoplasmic vacuolation in the infected cynomolgus monkey kidney cells (same as Plate-Fig. 2), hematoxylin-eosin staining, $\times 600$.

Fig. 4. Intranuclear inclusion bodies appeared in the infected cynomolgus monkey kidney cell culture (5th day), hematoxylin eosin staining, $\times 600$. Such type of inclusion-bodies was constantly observed in all batches of the infected cynomolgus MK cell cultures tested, without regard to the appearance of cytoplasmic vacuoles. 